\title{
RESUME PEMBUATAN PROGRAM APLIKASI BORLAND DELPHI7.0 BERBASIS PAPERLAIN
}

\section{VIVI ERYANI}

\section{4}

Universitas Mitra Indonesia, Sistem informasi

Vivieryani.student@umitra.ac.id

\section{ABSTRAK}

Secara umum pengertian ilmu komputer dapat dijabarkan sebagai sebuah disiplin ilmu yang mempelajari tentang seluk - beluk teknologi komputer mulai dari hardware atau bisa disebut dengan perangkat keras dan juga sofware yang bisa disebut juga dengan perangkat lunak. Akan tetapi dalam penerapannya Ilmu komputer sendiri menitik beratkan pada materi - materi yang berhubungan dengan pemrograman komputer, dan rekayasa perangkat lunak komputer. Sedangkan teknik komputer cenderung lebih menekankan pada pembelajaran mengenai perangkat keras komputer dan jaringan.

\section{CAPTURE PEMROGRAMAN :}

1. Fortal

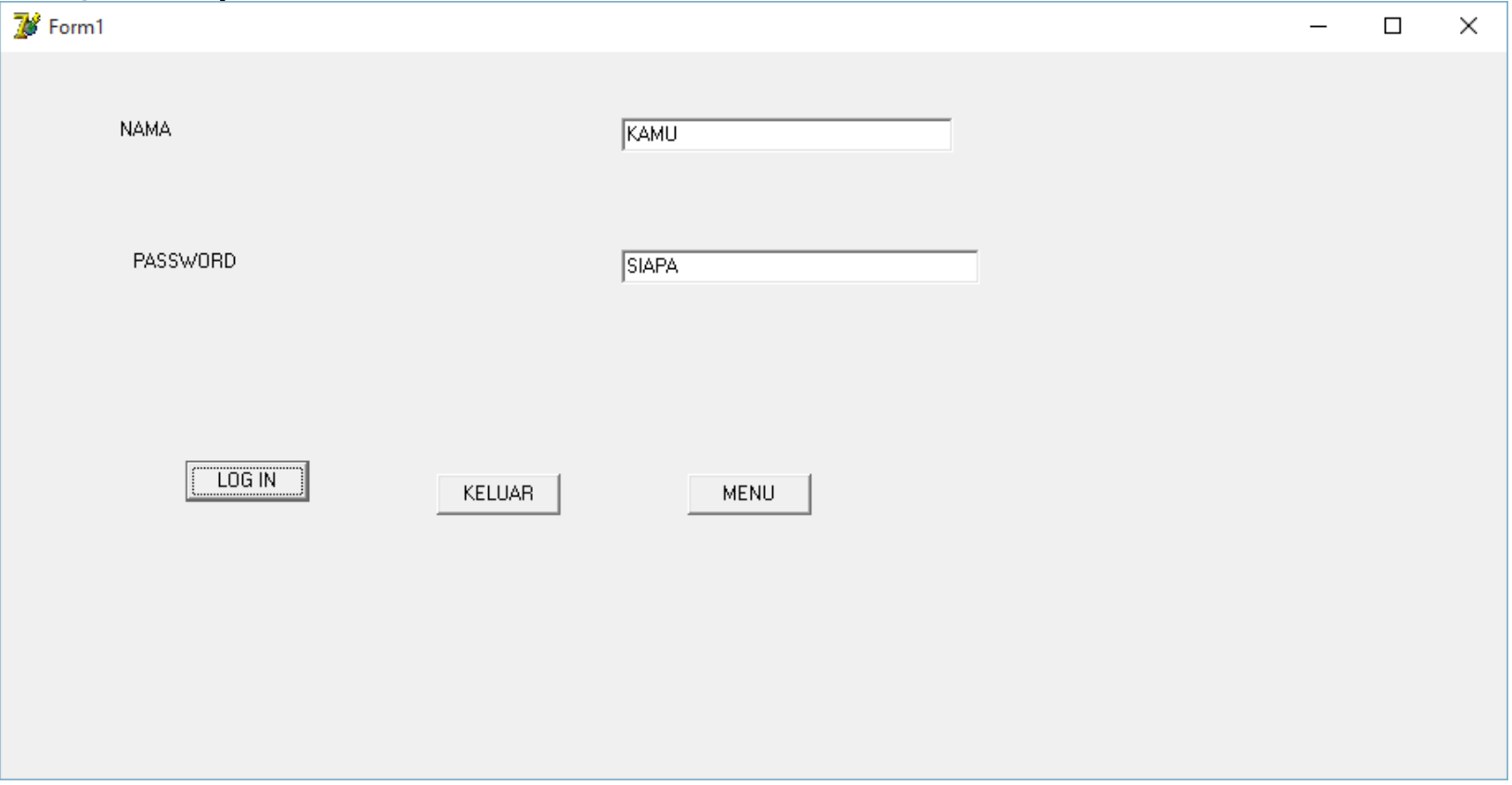


2. Menu

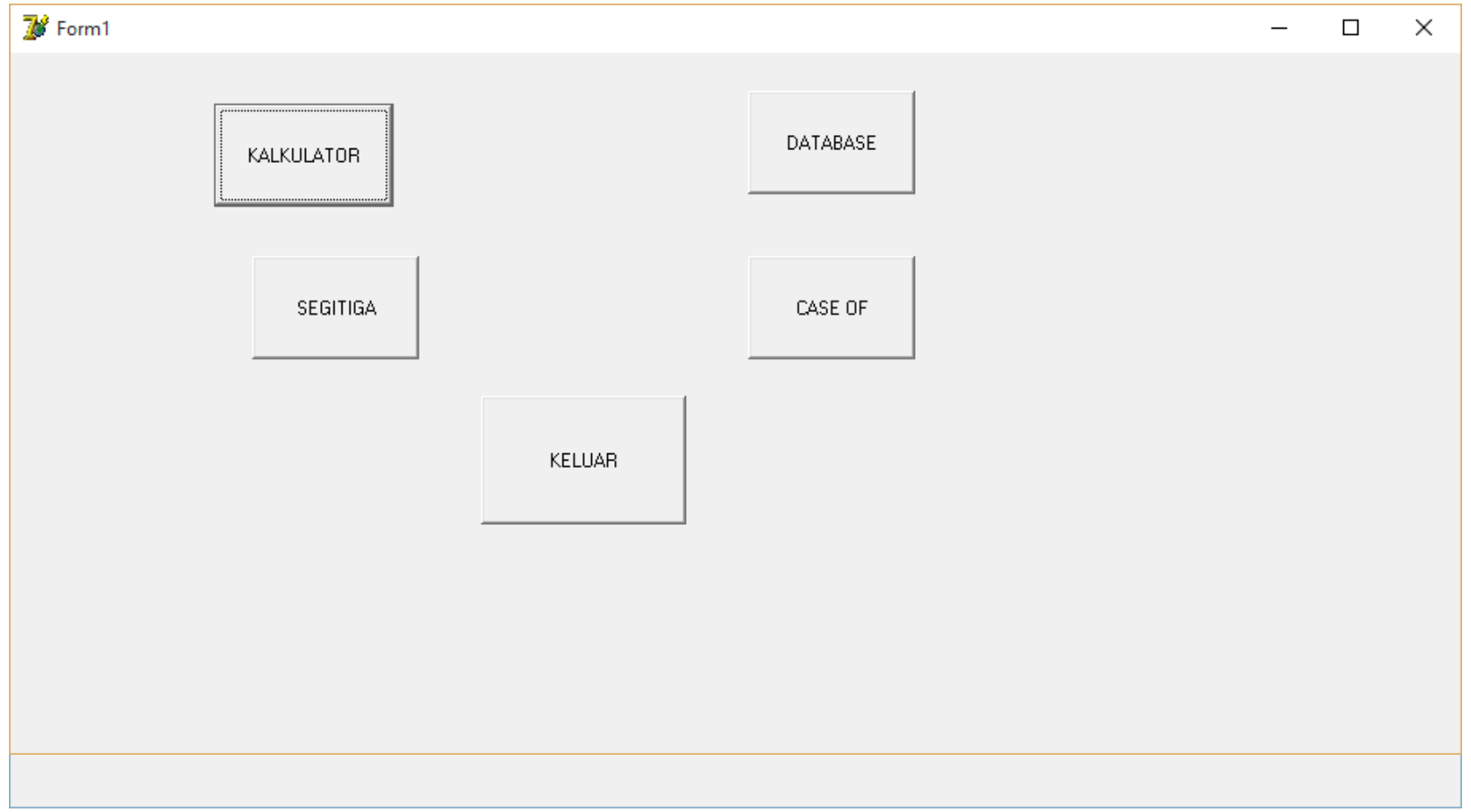

3. Kalkulator

BILANGAN 1

BILANGAN2

HASII

$$
9
$$

9

81
MENU

ULANG

KELUAR

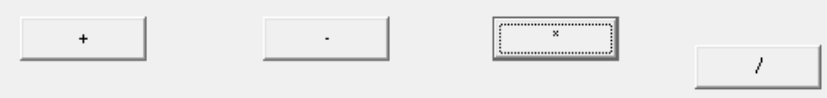




\section{Segitiga}

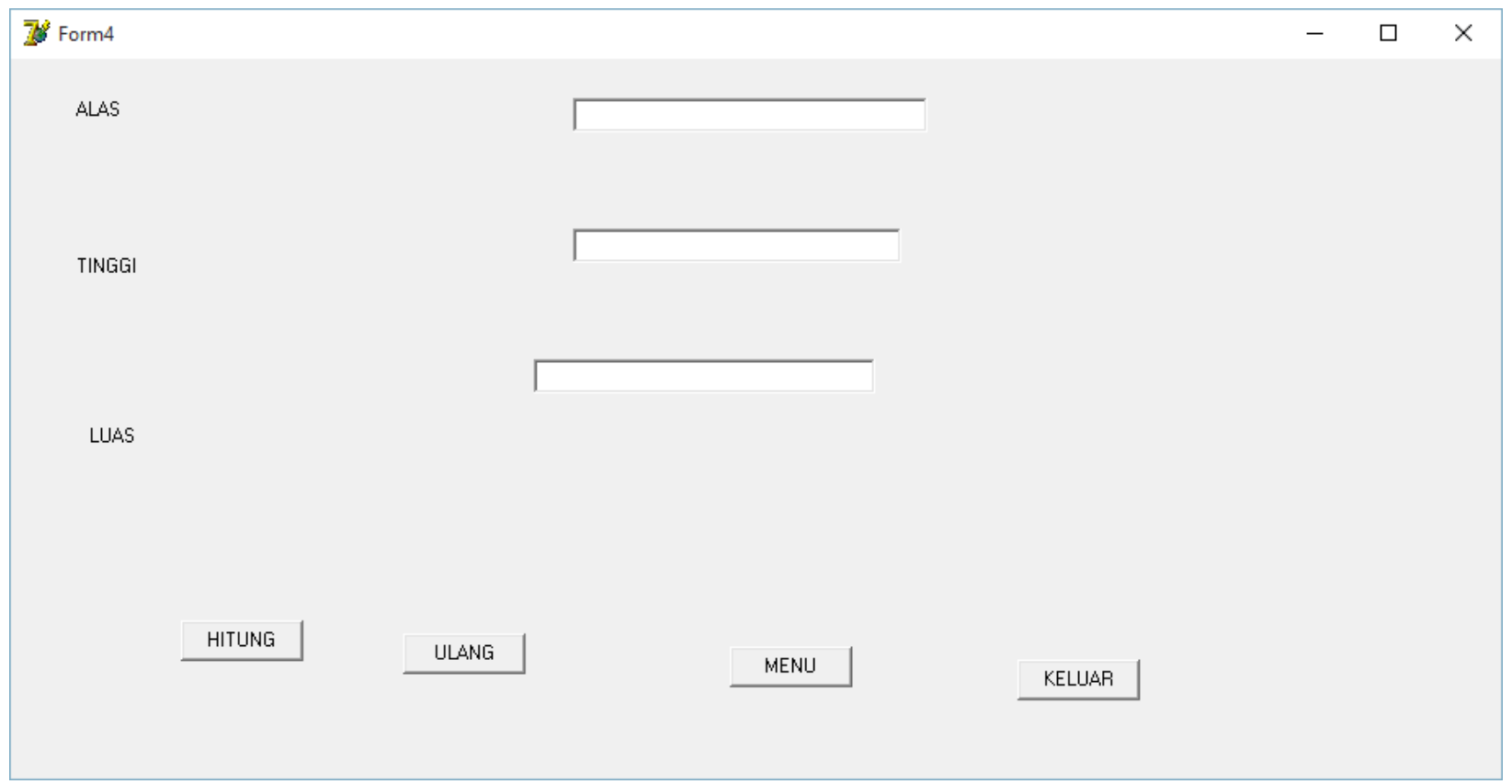

5. Case OF

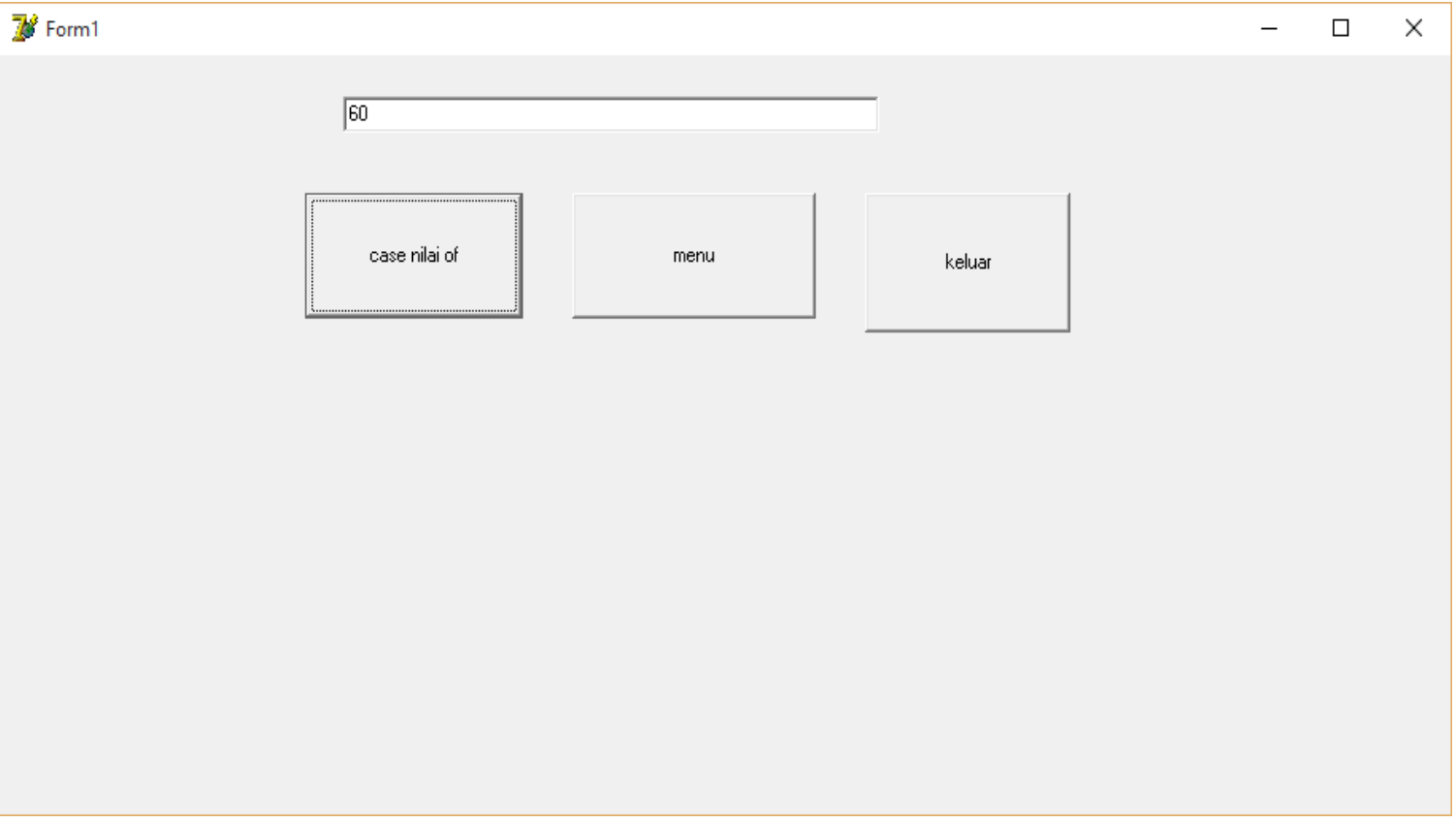




\section{Database}

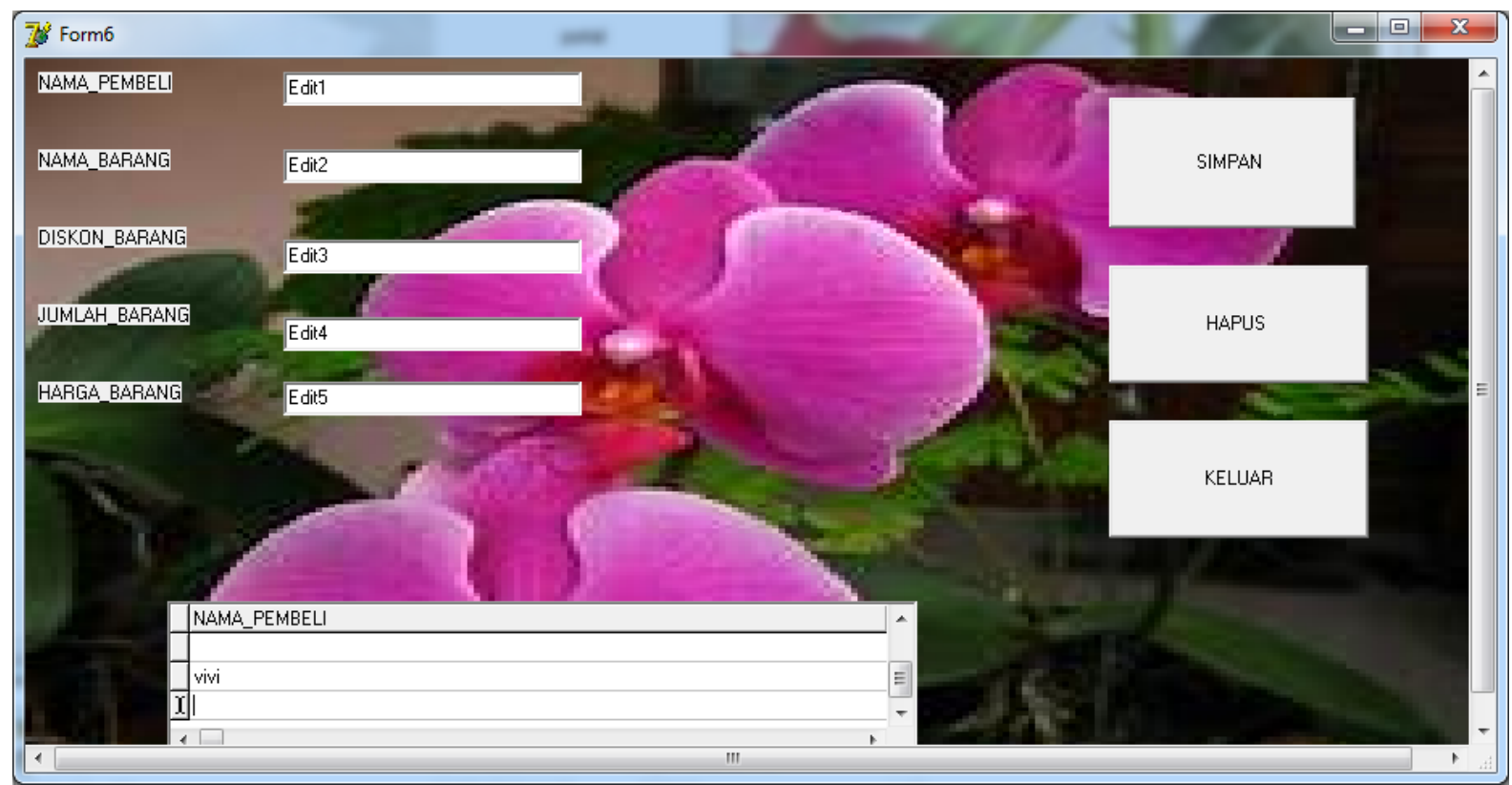

\section{PENJELASAN :}

\section{MENU}

Menu adalah

Merupakan kumpulan perintah yang sudah dikelompokkan menjadi satu, berdasarkan fungsinya masing masing,

\section{Portal}

Adalah penyedian kandungan informasi yang dapat diakses menggunakan beragam perangkat, misalnya computer pibadi, computer jinjing, (notebook) PDA (personal digital assistant) atau bahkan telepon genggam. 


\section{3. kalkulator}

Adalah alat untuk menghitung dari perhitungan sederhana seperti penjumlahan, pengurangan, perkalian, dan pembagian, sampai kepada kalkulator, sains yang dapat menghitung rumus matematika tertentu.

\section{Segitiga}

Adalah bangun datar yang dibentuk oleh 3 garis lurus yang saling berpotongan. Segitiga dibentuk oleh 3 titik sudut yang letak nya tidak segaris dihubungkan.

\section{Case Of}

Case of pada pascal, case of adalah bahasa pemrograman agar output pada pemrograman pascal mengikuti sesuai dengan input.

\section{Database}

Kumpulan data yang disimpan secara sistematis didalam computer yang dapat diolah atau dimanupulasi menggunakan perangkat lunak (program aplikasi ) untuk mengasil kan informasi.

\section{A. DISKUSI}

Bagi pemrogramer harus ada ketelitian jika ingin membuat sebuah data, dalam membuat data2 yang ada di delpi kita harus hati hati jika ingin memasuk kan coding, karena jika kita salah satu saja akibat 
nya data data yang kita buat akan salah ,

Dan jika tidak running atau debug, kita harus mencari dimana letak kesalahan kita itu.

\section{B. REFERENSI}

1. A. S. Putra And O. M. Febriani, "Knowledge Management Online Application In Pdam Lampung Province," In Prosiding International Conference On Information Technology And Business (Icitb), 2018, Pp. $181-187$.

2. A. S. Putra, O. M. Febriani, And B. Bachry, "Implementasi Genetic Fuzzy System Untuk Mengidentifikasi Hasil Curian Kendaraan Bermotor Di Polda Lampung," J. Sist. Inf. Dan Manaj. Basis Data, Vol. 1, No. 1, Pp. 21-30, 2018.

3. O. M. Febriani And A. S. Putra, "Sistem Informasi Monitoring Inventori Barang Pada Balai Riset Standardisasi Industri Bandar Lampung," J. Inform., Vol. 13, No. 1, Pp. 90-98, 2014.

4. Putra, Arie Setya. "2018 Artikel Struktur Data, Audit Dan Jaringan Komputer." (2018).

5. Putra, A. S. (2018, July 17). Paperplain Fundamental Create Application With Borland Delphi 7.0 University Of Mitra Indonesia. Retrieved From Osf.Io/Pbrn9. 
